\title{
A launder design method for thickened tailings
}

\author{
TG Fitton Fitton Tailings Consultants, Australia
}

\begin{abstract}
In mountainous terrain, thickened tailings slurries are often transported by gravity flow in open channel launders (also called channels or flumes). These launders are typically constructed of concrete, and can run for many kilometres, as they transport the tailings slurry from the mine to a tailings storage facility at a lower elevation. Some of the large copper mines of Chile and Iran feature such launders, with some notable examples being Andina, Chile (57 km, carrying some 70,000 dry tonnes per day), Chuquicamata, Chile (15 km with 200,000 dry tonnes per day), El Teniente, Chile (86 km, 130,000 tpd) and Sarcheshmeh, Iran (16 km, 60,000 tpd). The main advantage of such launders is the ability to avoid pumping of the slurry. In mines such as these, the cost of pumping such vast amounts of tailings would be considerable.
\end{abstract}

Launder cross-sections can come in many shapes, with common geometries being rectangular, trapezoidal and U-shaped. Circular pipes flowing partially full also function well as launders, and can offer certain advantages over the more common open-topped concrete sections.

This paper presents a simple method for designing launders for the gravity transport of tailings slurries. The method applies to both Newtonian and non-Newtonian slurries, and works on the basis that the slurry flow maintains sufficient velocity to avoid deposition of solid particles in the launder. With inputs of flow rate, slurry concentration, rheology, particle specific gravity and particle size distribution, the design method calculates cross-sectional dimensions for a launder of rectangular, trapezoidal or circular cross-section, and then calculates a minimum slope required for the total transport of the slurry.

\section{Introduction}

Launders (also called channels, sluices or flumes) are open channel structures that are used for the gravity transport of fluids. In the mining industry, launders have been in use for many years for the transport of tailings slurries. The main limitation of such launders is that they must maintain a certain minimum slope in order to keep the flow velocity above the solids deposition point, so it is essential that there is sufficient elevation difference between the upstream and downstream ends of the launder. However, launders have the significant advantage of not requiring any pumps or power to operate. Tailings launders are of limited value in flat terrain, but they certainly have been exploited in mountainous regions, such as in the South American Andes and in other mountainous mining locations. Some notable tailings launders include Andina, Chile ( $57 \mathrm{~km}$ distance, carrying some 70,000 dry tonnes per day), Chuquicamata, Chile (15 km with 200,000 dry tonnes per day), El Teniente, Chile (86 km, 130,000 tpd) and Sarcheshmeh, Iran (16 km, 60,000 tpd).

Launder cross-sections can come in many shapes, with common geometries being rectangular, trapezoidal and U-shaped. Typically, such launders are constructed of reinforced concrete, with smaller examples being fabricated in precast sections. Some photographs of concrete tailings launders are presented in Figures 1, 2 and 3. Circular pipes flowing partially full also function well as launders, and can offer certain advantages over open-topped concrete sections (no splashing, no ingress of debris or wildlife, less evaporation, often cheaper where labour is expensive). Excavated earthen channels and overland flow of tailings slurry (without any formed channel) could also be analysed with this method, though such unconfined flows can impact large areas of the environment whenever splashing and cascading occurs, and are not strictly classified as launders. 


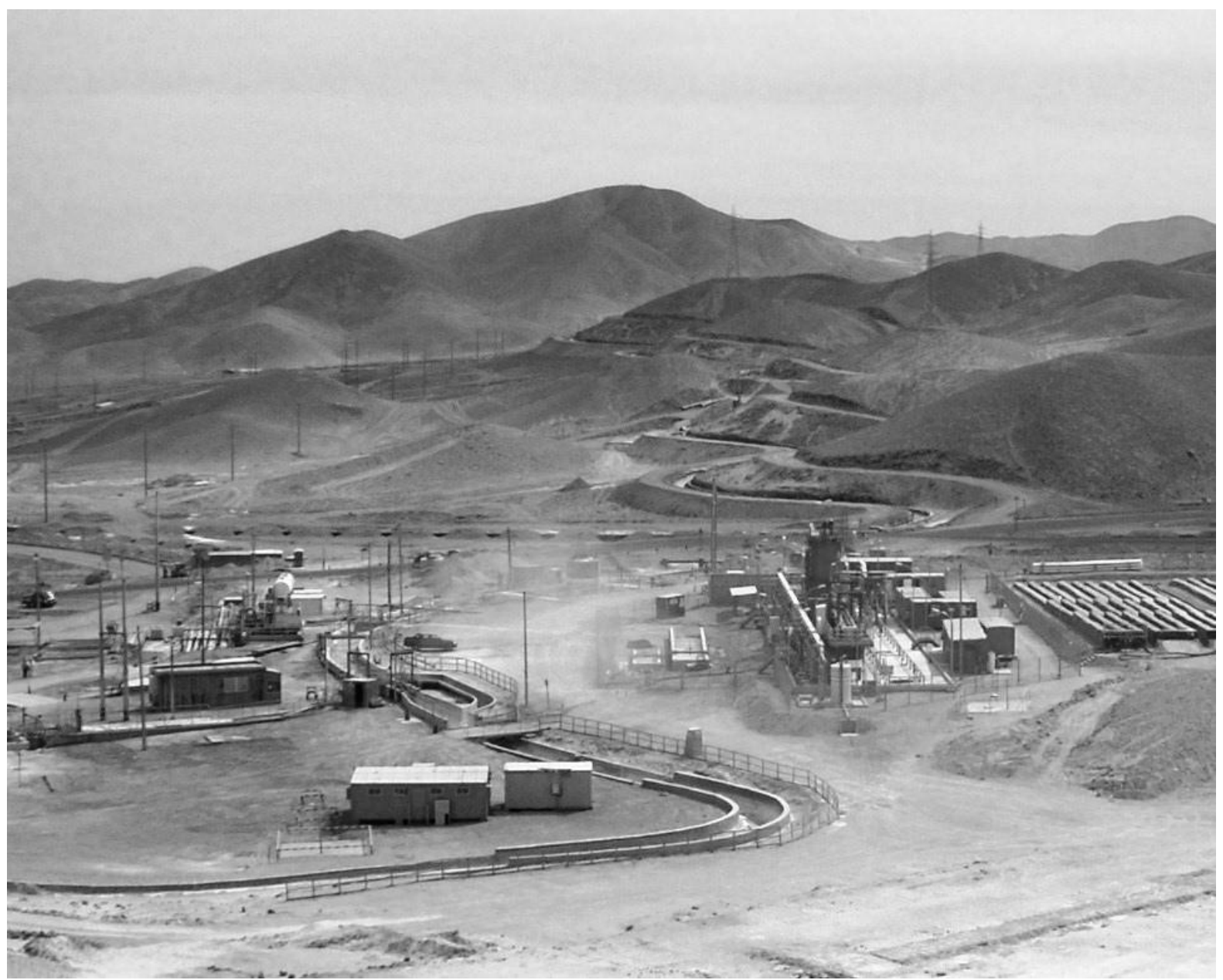

Figure 1 The tailings launder at the Chuquicamata copper mine, Chile

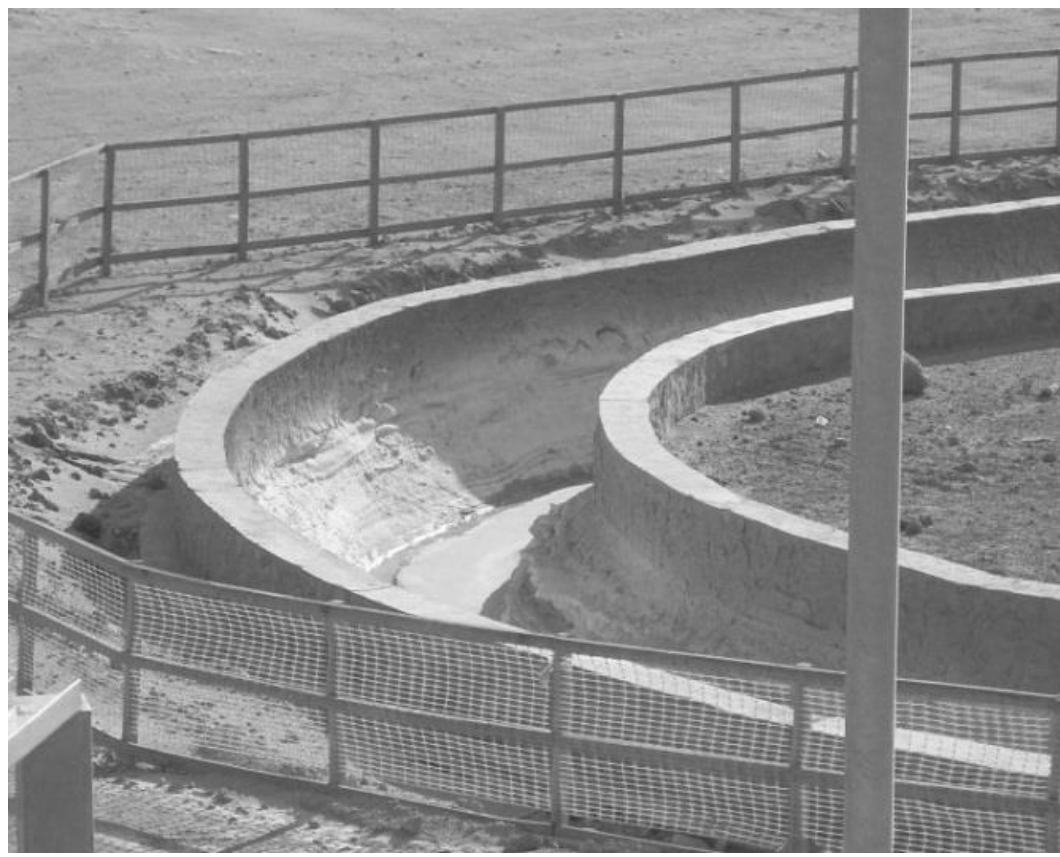

Figure 2 Chuquicamata launder. Its cross-section features a trapezoidal base 


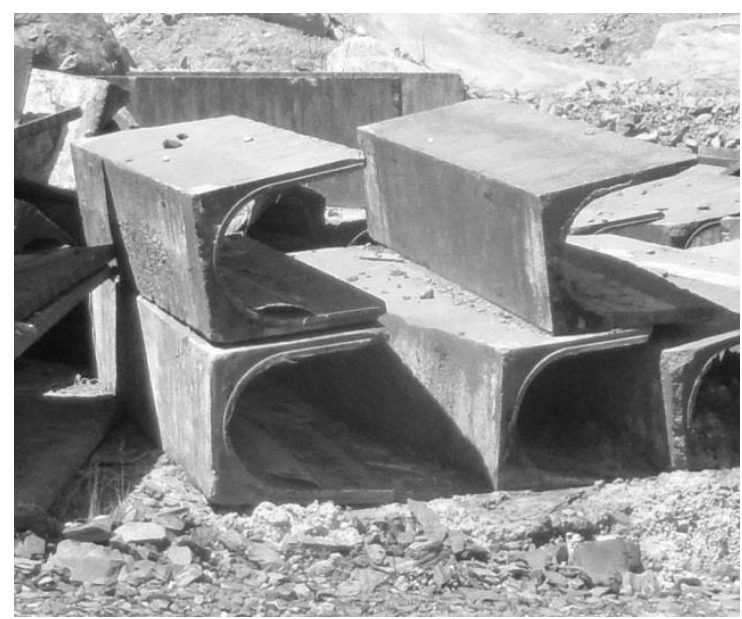

\section{Figure 3 Precast U-shaped sections from a tailings launder at a mine in Australia}

\section{Current state of the science}

The theoretical design of a tailings launder is not a simple process, particularly where thickened tailings are concerned. Open channel flows are not well understood, even in the relatively simple situations that feature water only. In the prediction of head losses, an empirical approach is still the modus operandi for the vast majority of practitioners. Even state-of-the-art hydraulic modelling software packages such as the Hydrologic Engineering Center's River Analysis System (HEC-RAS) (US Army Corps of Engineers 2015) rely on empirical equations such as Manning's equation to estimate the head losses in a system.

It is therefore not surprising that the consideration of a non-Newtonian fluid makes channel flow modelling even more difficult. With water, though the typical analysis approach is empirical, the calculated head losses are reasonably accurate and reliable. For non-Newtonian fluids such as thickened tailings slurry there is no 'default' method of analysis, and the problem has been approached from many directions. The Manning and Darcy-Weisbach equations have proven to be applicable to non-Newtonian flows (Lacey 1946; Fitton 2007), but the challenge is in the accurate estimation of a roughness coefficient (or friction factor) that encapsulates all of the non-Newtonian aspects of the fluid. A wide range of methods for the estimation of such a friction factor have been presented in the literature (Abulnaga 2002; Wasp et al. 1977).

Even the point of transition between laminar flow and transition flow is not well understood in open channel flows. In pipe flow, most experts agree that transition occurs around a Reynold's numbers of 2,100-2,300. In open channels, it has been found that the point of transition for non-Newtonian fluids can occur at Reynold's numbers as low as 500 and as high as 5,000 (Haldenwang 2003). Haldenwang (2003) proposed a method for the prediction of the transition point based on an empirical equation featuring the Froude and Reynold's numbers. Slatter (2013) presented a sheet flow approach to the analysis of viscoplastic fluids and proposed a critical Reynold's number of 700 for the transition point, calculated with a new equation for Reynold's number. Both methods are somewhat complex to apply. Others have presented simpler and cruder approaches, such as assuming transition occurs at the intersection point between the Hagen-Poiseuille equation and the Colebrook-White equation (Fitton 2008).

To complicate matters more, tailings slurries are non-Newtonian fluids that typically feature settling particles, so this drives engineers even further into the realms of empiricism as they attempt to estimate the amount of turbulence required to keep the particles from settling and forming a stationary bed in the launder.

It is therefore no mean feat to design a launder for long-distance transport of thickened tailings slurries. Many designers would lean towards experimentation with a test flume before committing to any design.

However, at the conceptual engineering and pre-feasibility level, flume testing is generally not warranted, but there is still a need for reasonable estimates for launder design. This paper sets out to provide a useful 
approach for first-pass launder design calculations, by presenting a reasonably simple method for predicting an indicative size and slope for a launder.

\section{Development of a launder design method}

The launder design method was developed by building an a priori model and then simplifying it with empiricism. A large number of relevant transport velocity equations were identified in the literature, and from this a shortlist of five were taken up for further investigation; those chosen were Wasp et al. (1977), Thomas (1979), Lacey (1946), Fitton (2007) and Oroskar and Turian (1980). Two head loss equations were included in the investigation (Manning and Darcy-Weisbach), and two friction factor equations were also tested (Colebrook-White and Blasius). Though these models would generate 20 different combinations if one of each type was used for each test, numerous combinations of the transport velocity models were also tested using a 'largest of the two' (or three or four or five) models approach, which generated many more combinations.

As discussed earlier, the calculation of a transition velocity for a non-Newtonian open channel is a complex task. For a detailed launder design, it should be calculated, but the objective of this paper is to present a simple method of launder design, so no attempt has been made to estimate the transition velocity (or transition point in terms of Reynold's number or any other criterion). Instead, the launder design method presented herein simply focuses on the transport velocity, assuming that the velocity is above the transition point.

\section{$4 \quad$ Validating data}

The testing of each combination of equations involved validating the predicted launder slopes against some relevant data. The data used for validation was gathered in three separate flume trials by the author and his colleagues; The first two sets of data were gathered at the Peak gold mine and the Sunrise Dam gold mine (Fitton 2007), and the third set was gathered at the Chuquicamata copper mine (Pirouz et al. 2013).

It is noted that the flume experiments carried out at Peak and Chuquicamata consisted of self-formed channel experiments and half-pipe flume experiments. The self-formed channel experiments were relevant to the channels that form on tailings beaches, but these data are of limited use in validating a launder design, as the channel cross-sectional shapes were not known in those experiments. However, all three experimental campaigns also included experimentation with a half-pipe flume with a circular cross-section, which is not only useful for validating a beach slope prediction model, but also very useful for validating a launder design method.

The flume experiments set out to find the equilibrium slope for a range of slurry flows. This equilibrium slope is defined as the slope at which there is a net balance between erosion and sedimentation in the channel bed. It is therefore directly applicable to the design of a launder for slurry transport, as it is of prime importance that a launder is constructed at a slope that is steeper than this equilibrium slope in order for total transport of the slurry to occur.

\section{$5 \quad$ Selection of a series of equations to build a model}

The validation exercise set out to identify the most accurate combination of equations, but accuracy did not always favour complexity. Some of the simpler approaches predicted the channel slope reasonably well, so these were given higher value to enable the final method to be simpler.

Some comparisons for the reader to see the relative accuracy of the different approaches can be found in Fitton (2007). The selected model featured the Wasp et al. (1977) minimum transport velocity equation in the form published in Fitton (2007), the Darcy-Weisbach equation for estimation of head losses, and the Blasius equation for the estimation of the Darcy friction factor.

The Wasp et al. (1977) equation, as presented in Fitton (2007), is as follows: 


$$
V_{c}=3.8 C_{v}^{1 / 4}\left(\frac{d_{50}}{4 R_{H}}\right)^{1 / 6}\left(\frac{8 g R_{H}\left(\rho_{s}-\rho_{l}\right)}{\rho_{l}}\right)^{1 / 2}
$$

Where:

$$
\begin{aligned}
& C_{V} \quad=\text { volumetric concentration of solids, expressed as a fraction. } \\
& d_{50} \quad=\text { median particle diameter, expressed in metres. } \\
& R_{H} \quad=\text { hydraulic radius, expressed in metres. } \\
& \rho_{s} \quad=\text { density of solids }\left(\mathrm{kg} / \mathrm{m}^{3}\right) . \\
& \rho_{l} \quad=\text { density of the decant water }\left(\mathrm{kg} / \mathrm{m}^{3}\right) .
\end{aligned}
$$

The Darcy-Weisbach equation is as follows:

$$
S=f_{D} V^{2} /\left(8 g R_{H}\right)
$$

Where:

$$
\begin{aligned}
f_{D} & =\text { Darcy friction factor. } \\
V & =\text { average velocity }(\mathrm{m} / \mathrm{s}) . \\
g & =\text { acceleration due to gravity }\left(\mathrm{m} / \mathrm{s}^{2}\right) .
\end{aligned}
$$

The Blasius equation:

$$
f_{D}=0.3164 R e^{-0.25}
$$

Where:

$$
R e=\text { Reynold's number for the flow. }
$$

The Wasp et al. model was found to be reasonably accurate in modelling non-segregating tailings (like some of the others), and also in modelling segregating flows (unlike some of the others). This allows the launder design method to be applied without any need to consider the segregation behaviour of the slurry.

\section{$6 \quad$ Empirical simplification of the selected model to develop the design method}

During the investigation of models from the literature, all of the assessed models were found to be sensitive to the rheological characteristics of each slurry, the depth of flow in the channel, the channel cross-section, the specific gravity of the solids and the decant water, the particle size distribution, and the flow rate. Due to that sensitivity, a change in any one of the parameters had a consequential effect on the predicted launder slope, and required other aspects of the model to be adjusted to compensate. It is for this reason that open channel flow modelling usually requires an iterative approach.

However, it is this sensitivity that makes the best design methods powerful and accurate. Too much empirical simplification can cause a model to become insensitive to the parameters listed above, rendering it case-specific, and causing it to predict poorly when applied to a different situation.

Therefore, in developing the current launder design method, it was desired that the sensitivity of the model would not be lost, but with the iteration avoided, and the number of equations and complexity of equations minimised.

Calculation of the channel cross-sectional area and wetted perimeter to determine a hydraulic radius has been overstepped with a single empirical equation that relates the flow rate to the hydraulic radius, which enables the usual initial estimates of flow depth to be abandoned too. Similarly, the iterations of calculations that accompany the use of the implicit Colebrook-White equation have been replaced with the simpler Blasius equation, albeit slightly less accurate than the former. 


\section{$7 \quad$ Launder shapes}

The launder design method has been validated for the following cross-sectional shapes: rectangle, trapezoid with 1 in 1 side slopes, trapezoid with $2 \mathrm{~V}: 1 \mathrm{H}$ side slopes, and a circular pipe flowing partially full.

Each of the shapes is defined as shown in Figure 4.

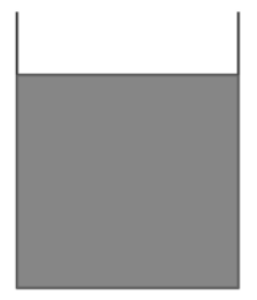

W

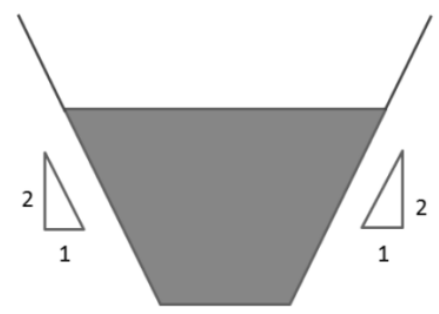

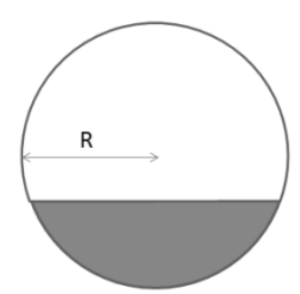

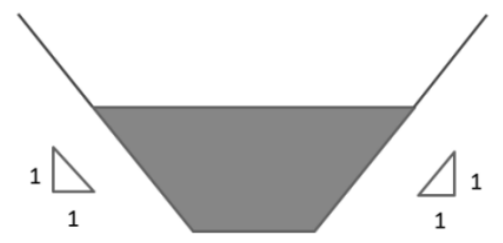

B

Figure 4 The four launder shapes considered: rectangle, circle, $2 \mathrm{~V}: 1 \mathrm{H}$ trapezoid and 1:1 trapezoid

A key dimension was defined for all four shapes ( $W$ for the rectangle width, $R$ for the radius of the pipe, and $B$ as the base width for both trapezoids. The depth of flow is one of the outputs from the launder design method.

\section{Aspect ratio}

For rectangular open channels, an aspect ratio around 1:1 was targeted. This was felt to be most efficient in terms of construction cost and maintenance. For trapezoidal open channels, an aspect ratio around $1 \mathrm{H}: 1.5 \mathrm{~W}$ was targeted for the same reasons. For the circular launder, a centreline depth to diameter ratio of 1:3 was targeted to avoid full pipe flow occurring in the launder. Full pipe flow would not only see the model lose validity, but it would also result in higher velocities and higher pipe wear.

One empirical equation was developed for calculating the key dimension for all shapes:

$$
W=R=B=30 Q^{0.5}
$$

Where:

$$
\begin{array}{ll}
Q & =\text { flow rate, expressed in litres per second. } \\
W, R \text { or } B & =\text { parameter, expressed in millimetres. }
\end{array}
$$

Equation 1 generally achieved the target aspect ratios for the experimental flume data that was used to validate the method, but it is expected that larger flow rates $(>100 \mathrm{~L} / \mathrm{s})$ will see the aspect ratio of the flow become wider and shallower, for any shape that is selected. This is acceptable in consideration of the method's purpose.

During the development of the design method, it was observed that all four cross-sections displayed similar relationships between the flow rate and the hydraulic radius. This suggests that the selected model is not 
particularly sensitive to channel shape, for any given flow rate. This finding was exploited with the adoption of an empirical equation to predict the hydraulic radius $\left(R_{H}\right)$ for all of the featured cross-sectional shapes as a function of the flow rate.

$$
R_{H}=0.014 Q^{0.4}
$$

Where:

$Q \quad=$ expressed in litres per second.

$R_{H}=$ hydraulic radius, expressed in metres.

\section{$9 \quad$ Application of the launder design method}

After calculating the hydraulic radius for a launder (Equation 2), the remaining steps for applying the design method are as follows:

- Calculate the transport velocity using the Wasp et al. (1977) equation (Equation 1).

- Determine the Reynold's number Re, using the definition of Re for a Herschel-Bulkley fluid (Haldenwang 2003).

$$
R e_{H B}=\frac{8 \rho V^{2}}{\tau_{y}+K\left(\frac{2 V}{R_{H}}\right)^{\eta}}
$$

Where:

$$
\begin{aligned}
\rho & =\text { density of the slurry mixture }\left(\mathrm{kg} / \mathrm{m}^{3}\right) . \\
V & =\text { velocity, as calculated with the Wasp et al. equation }(\mathrm{m} / \mathrm{s}) . \\
\tau_{y} & =\text { Herschel-Bulkley yield stress }(\mathrm{Pa}) . \\
K & =\text { Herschel-Bulkley consistency index }\left(\mathrm{Pa} . \mathrm{s}^{\mathrm{n}}\right) . \\
n & =\text { Herschel-Bulkley model flow behaviour index (no units). }
\end{aligned}
$$

The Darcy friction factor is then calculated using the Blasius equation (Equation 3), and the Darcy-Weisbach equation (Equation 2) is used to determine a launder slope.

The size of the launder is defined in terms of the key dimension and the depth of flow. Equation 1 can be used for determining the key dimension of the launder cross-section. To calculate the approximate depth of the flow in each of the four featured cross-sections, the following empirical relationships can be used:

$$
\begin{gathered}
\text { Depth } h_{\text {circle }}=1.60 R_{H}^{0.95} \\
\text { Dept } h_{\text {rectangle }}=1.15 R_{H}^{0.75} \\
\text { Depth }_{\text {trapezoid 1:1 }}=1.32 R_{H}^{0.93} \\
\text { Depth }_{\text {trapezoid 2:1 }}=1.34 R_{H}^{0.89}
\end{gathered}
$$

It is noted that the predicted depth assumes uniform steady state flow. For the practical design of an open channel launder, additional side wall height will need to be provided, especially at any changes in the launder direction, where sloshing or overtopping is expected at the outer walls. Any possible higher flow rates should also be considered at this point too.

\section{Accuracy of design method}

The launder design method has been applied to predict the flume slopes and cross-sectional areas that were measured in the validating data. A plot of the launder slope predictions is presented as Figure 5, with another plot comparing the predicted cross-sectional to those observed in the flume as Figure 6. 


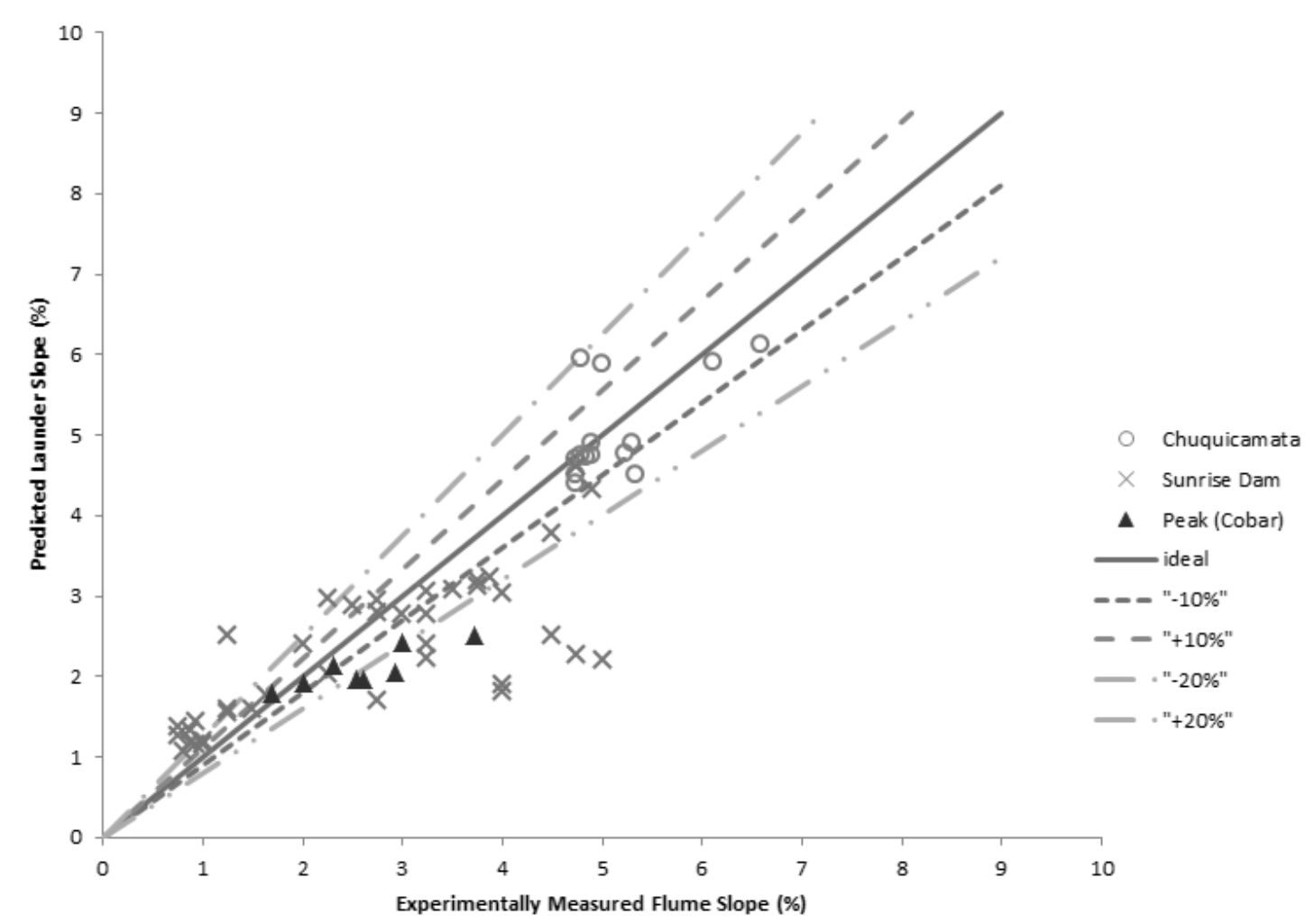

Figure 5 A plot showing the predicted launder slope in comparison to the observed flume slopes for the same flows

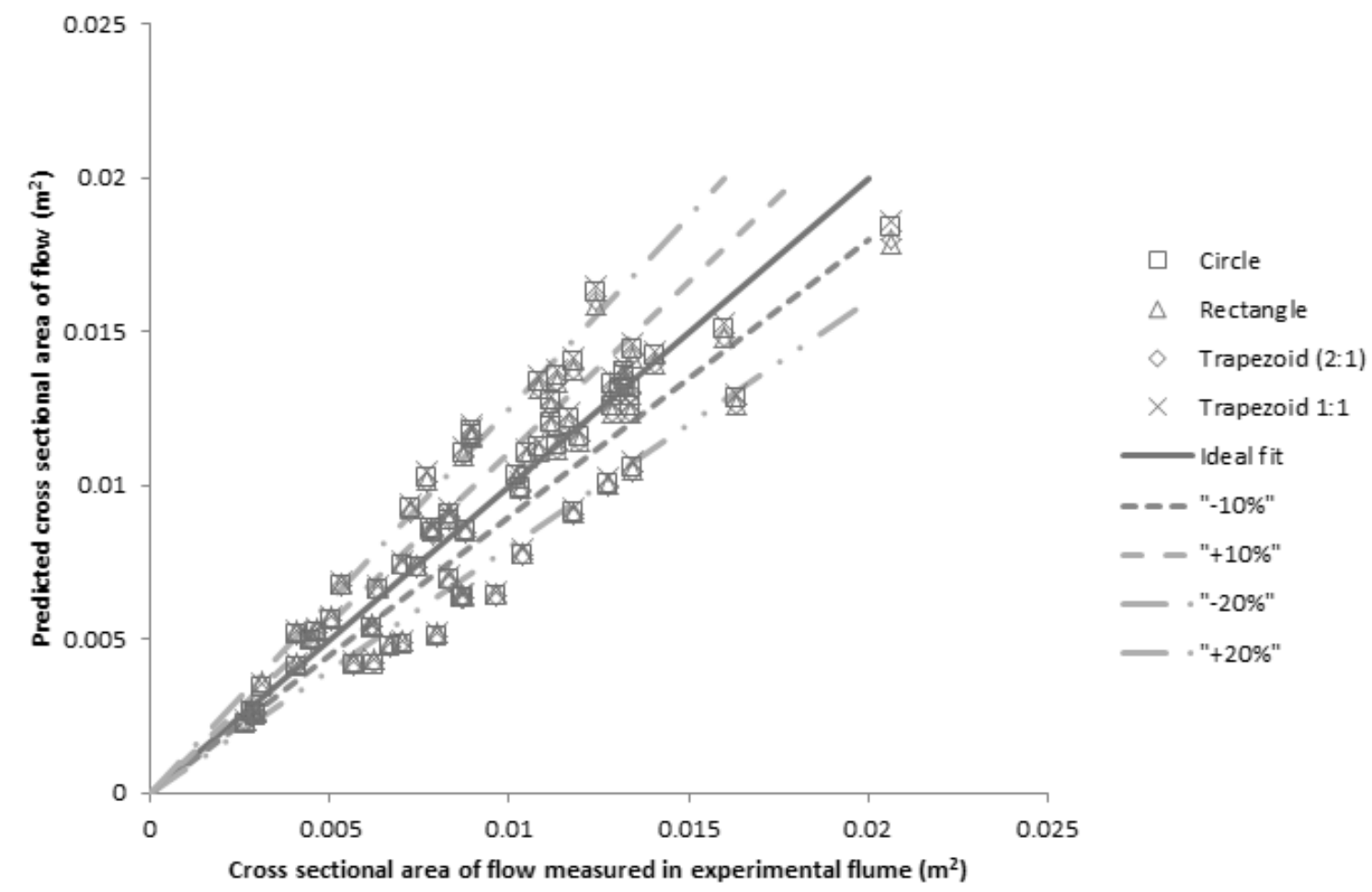

Figure 6 A plot showing the predicted cross-sectional area of the flow in comparison to the observed flume cross-sectional areas for the same flows

Figure 5 indicates that the launder design method predicts launder slopes reasonably well in comparison to the experimental flume data. There is some scatter in the data, but the method's predictive accuracy is 
deemed to be sufficient for its intended purpose of a conceptual and prefeasibility level study. Furthermore, it is noted that the cross-sectional shape of the flume did not match all of the four cross-sections featured in this paper (the flume being circular); despite this, the method still predicted the flume slope to a useful degree of accuracy. This finding shows that the method has very low sensitivity to cross-sectional shape, and is therefore quite robust in its applicability to other cross-sections.

Figure 6 shows the predicted cross-sectional area of the flows, calculated from the depth and key dimension values that were predicted using the design method, employing the appropriate geometric equations for each cross-sectional shape. The first finding of this exercise is that all four of the predicted areas for each flow regime are very similar, irrespective of the shape used. This further reinforces the previous observation that the method is not sensitive to channel shape, and indicates that cross-sections can be modified somewhat without upsetting the accuracy of the prediction, providing the area remains constant. The second observation from this plot is that the predicted cross-sectional areas are reasonably similar to the areas deduced from the depths measured in the flume experiments, with the data generally falling reasonably accurately along the ideal fit line without any obvious under or over-prediction of the launder size. This provides further confirmation that the accuracy of the design method is sufficient for its intended purpose at conceptual and pre-feasibility study level.

\section{Factor of Safety}

For the design of a pipeline, one would usually try to keep the flow in the turbulent regime at a velocity that is greater than the predicted deposition velocity. The degree of overestimation is usually defined by the adoption of a nominal Factor of Safety. The design process would entail predicting the transition velocity and the deposition velocity, and then applying the safety factor to the larger of the two numbers to arrive at a design velocity.

For the design of a tailings launder, a similar approach could be applied, but it is argued that this launder design method is not accurate enough to warrant it. As can be seen in the fit plot for the predicted launder slopes (Figure 5), there is a considerable amount of scatter in the points. The validating experimental data itself certainly has its own inherent error, but it is asserted that some of the scatter can also be attributed to the inaccuracy of the prediction method. The majority of the points indicate that the model makes reasonable predictions, but the worst outliers indicate predicted slopes that are as much as double and as little as half of the observed flume slopes. This equates to error as great as $+100 \%$ and $-50 \%$, which is far greater than the 1.1-1.25 Factor of Safety that is typically applied in pipeline design scenarios. It is for this reason that no Factor of Safety is included in this method, though the user is free to add some margin to the predicted launder slope as they see fit. However, it is important to note that in launder flow, as in pipeline flow, particles will segregate in laminar flow, and the designer needs to be confident that the flow regime is such that particles are transported along the launder and do not form a stationary deposit.

\section{Other cross-sectional shapes}

The launder design method has been presented for approximating the flow depth in four cross-sectional shapes. However, it can be applied to give depth approximations for any other cross-sectional shape if a trial-and-error approach is taken as follows:

- Assume a channel depth.

- Calculate the hydraulic radius as the ratio of the cross-sectional area and wetted perimeter.

- Adjust the depth until the hydraulic radius is equal to that calculated with Equation 2.

\section{Conclusions}

A launder design method has been presented, which can be applied to any cross-sectional shape. Empirical equations have been presented to allow channel depths to be estimated for four common launder cross-sectional shapes. Validation of the method has been provided by comparing predicted launder slopes 
with flume slopes that were measured in three relevant experimental campaigns, as well as comparing the predicted cross-sectional areas with those observed in the flume experiments. Both compare reasonably well. The method is simple to apply but retains the sensitivity and accuracy of the more complex design approach that it was adapted from.

The model is not sensitive to minor changes in the cross-section (so long as the cross-sectional area remains constant), so the cross-section can be modified from that predicted by the model without any major consequence.

\section{References}

Abulnaga, BE 2002, Slurry systems handbook, McGraw-Hill Professional Publishing, New York.

Fitton, TG 2007, 'Tailings beach slope prediction', PhD thesis, RMIT University.

Fitton, TG 2008, 'Non-Newtonian open channel flow - a simple method of estimation of laminar/turbulent transition and flow resistance', in AB Fourie, RJ Jewell, P Slatter \& A Paterson (eds), Proceedings of the Eleventh International Seminar on Paste and Thickened Tailings, Australian Centre for Geomechanics, Perth, pp. 245-252.

Haldenwang, R 2003, 'Flow of non-Newtonian fluids in open channels', D.Tech. thesis, Cape Technikon.

Lacey, G 1946, 'A general theory of flow in alluvium', Journal of the Institution of Civil Engineering, vol. 27, pp. 16-47, and vol. 28, pp. 425-451.

Oroskar, AR \& Turian, RM 1980, 'The critical velocity in pipeline flow of slurries', AlChE Journal, vol. 26, no. 4, pp. 550-558.

Pirouz, B, Seddon, KD, Pavissich, C, Williams, MPA \& Echevarria, J 2013, 'Flow through tilt flume testing for beach slope evaluation at Chuquicamata Mine Codelco, Chile', in RJ Jewell, AB Fourie, J Caldwell \& J Pimenta (eds), Proceedings of the 16th International Seminar on Paste and Thickened Tailings, Australian Centre for Geomechanics, Perth, pp. 457-472.

Slatter, PT 2013, 'Analysis and flow behaviour prediction of paste material in sheet flow', in RJ Jewell, AB Fourie, J Caldwell \& J Pimenta (eds), Proceedings of the 16th International Seminar on Paste and Thickened Tailings, Australian Centre for Geomechanics, Perth, pp. 473-480.

Thomas, AD 1979, 'Predicting the deposit velocity for horizontal turbulent pipe flow of slurries', International Journal of Multiphase Flow, vol. 5, pp. 113-129.

US Army Corps of Engineers 2015, 'Hydrologic Engineering Centers River Analysis System', US Army Corps of Engineers, Davis, http://www.hec.usace.army.mil/software/hec-ras/

Wasp, EJ, Kenny, JP \& Gandhi, RL 1977, Solid-liquid flow slurry pipeline transportation, Trans Tech Publications, Clausthal-Zellerfeld. 